\title{
Les effets pervers de l'hyperrelativisme culturel
}

\section{Le droit et le contexte culturel peuvent-ils faire bon ménage ?}

\section{«Il est plus difficile de désagréger un préjugé qu'un atome.» - Albert Einstein}

Yao Assogba

Sociologue et professeur au département de travail social et des sciences sociales de l'Université du Québec en Outaouais

[Autorisation de reproduire accordée aux Classiques des sciences sociales par l'auteur le 11 janvier 2004]

Courriel : yao.assogba@uqo.ca

Le relativisme culturel de mauvais aloi, qui semble pointer son nez de temps à autre dans le domaine de la justice au Québec, peut induire à des idées, des croyances ou des pratiques susceptibles de briser la cohésion sociale et même constituer une menace à la démocratie.

Voici trois faits survenus entre 1994 et 2003. En 1994, la juge Raymonde Verreault avait pris en compte des «facteurs culturels» pour condamner à 23 mois de prison un homme d'origine algérienne reconnu coupable d'avoir sodomisé sa belle-fille de neuf ans. En 1998, la juge Monique Dubreuil avait dit prendre en considération le «contexte culturel» pour prononcer une sentence de 18 mois avec sursis applicable à deux hommes d'origine haïtienne reconnus coupables de viol collectif.

En novembre dernier, c'était au tour de l'avocat Yves-André Boutillier, dont le client d'origine haïtienne était accusé de proxénétisme eu égard à des mineures, de déclarer que «la prostitution fait partie de la culture haïtienne, tout comme fumer fait partie de la culture jamaïcaine». Que les stigmates ont la vie dure !

Pourquoi, dans ces cas, imposer des peines atténuantes par rapport à celles dont auraient écopé des «pure-laine», par exemple ? Pourquoi, dans une société comme le Québec, la justice tend-elle parfois à faire un rapprochement entre le droit et de prétendus comportements culturels de citoyens reconnus coupables d'actes de barbarie ? Ces trois cas participent à 
mon avis d'un hyperrelativisme culturel qui n'a pas sa raison d'être en démocratie. Jamais, dans un tel régime, ne devrait-on relativiser des actes de barbarie, qui portent atteinte à la dignité et à l'intégrité humaines, fûtce au nom d'une supposée culture.

\section{Reconnaître sans}

\section{renoncer}

En gros, le relativisme culturel soutient que les membres d'une communauté et leurs valeurs sont enfermés de manière irrémédiable dans des systèmes culturels singuliers : à chaque communauté sa culture, et à chaque culture ses valeurs. Dans cette perspective, nos sociétés démocratiques de plus en plus multiculturelles ne seraient qu'un incommensurable «assemblage» de ghettos. Mais l'égalité étant la valeur fondamentale de la démocratie, c'est l'égalité et elle seule qui demeure commune à tous les individus et à toutes les communautés vivant dans une société démocratique.

Le relativisme culturel suppose donc, en principe et dans les faits, que toutes les personnes, toutes les communautés et toutes les cultures dans la société soient traitées sur le même pied. Cependant, on sait que les opinions sur des pratiques sociales, des événements, etc., différencient les individus et les groupes. Les cultures aussi accordent des valeurs différentes aux objets, aux faits, etc. Le reconnaître ne signifie cependant pas qu'il faille renoncer aux valeurs humanistes communes d'une société donnée, particulièrement celles que ses lois reflètent.

Ce qui transparaît dans les cas cités relève à mon avis d'une hypertrophie et d'un détournement d'un sain relativisme culturel. Pourquoi cela au Québec ? Sans doute parce que nous vivons dans une démocratie où le relativisme culturel tend à imprégner la justice et la plupart des institutions des sociétés contemporaines (santé, éducation, médias, etc.) au nom de la rectitude politique ou de ce que le philosophe Charles Taylor appelle «la bienveillance universelle».

Ainsi, des femmes et des hommes de droit participent par leurs jugements à un relativisme culturel de mauvais aloi. Ils les ont étayés en invoquant des préjugés raciaux sur l'autre (en l'occurrence les peuples négroafricains) qu'ils ont puisés dans le tréfonds de l'imaginaire que l'EuropeOccident s'est fabriqué sur ces peuples à partir du XVIe siècle et qui ont été légitimés au cours des siècles suivants jusqu'à nos jours.

\section{Renforcer les préjugés}

Dans une société démocratique pluriculturelle, le relativisme pose des problèmes dès lors qu'en éthique on pose, d'une part, l'universalité des droits de la personne et, d'autre part, le droit à la différence des «singularités culturelles» (imaginaires ou réelles) mais dont les pratiques portent atteinte à la dignité de la personne. Dans ce cas, le relativisme peut produire de redoutables effets pervers. Par exemple, cela peut renforcer les préjugés à l'endroit de certaines communautés et cultures et pérenniser leur stigmatisation.

Ces faits sont d'autant plus injustes que les actes barbares «relativisés» par l'institution judiciaire au nom de la «singularité du système culturel des coupables» choquent les sentiments moraux des individus et la sensibilité morale du public, y compris celle des gens appartenant au même système culturel particulier.

Je veux bien dire oui au respect de l'individu, oui au respect de la dignité de l'autre et oui au respect de la 
diversité culturelle. Mais je m'oppose vivement à la barbarie qui hante depuis toujours les êtres humains, de quelque source qu'elle provienne. La relativiser ne fait que nourrir la stigmatisation dont sont victimes des personnes et communautés entières et ralentir la marche des peuples vers ce que le sociologue allemand Georg Simmel appelle la morale universelle, qui doit transcender les singularités culturelles comme certaines barbaries, extravagances et pratiques bizarres pouvant être jugées universellement inhumaines. La société québécoise se doit de remettre ces dérives en question. 